\title{
Aspectos da difusão lexical
}

\author{
MARCO ANTÔNIO DE OLIVEIRA \\ Universidade Federal de Minas Gerais
}

\section{Abstract}

In this text we discuss the rôle of the phonetic context in sound changes. Our position is that the phonetic context will act only a posteriori, as a possible stabilizer of innovations, and not a priori, as a trigger of sound changes. This being the case we argue that we can deal with phonetic effects even in a diffusionist approach to sound changes. Finally, we suggest that this approach leads to a considerable reduction of the scope of variation. 


\section{INTRODUÇÃO}

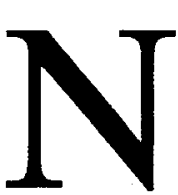

as duas últimas décadas surgiram na literatura lingüistica vários trabalhos, fundamentados em dados de diversas línguas, que vieram consolidar o modelo da Difusão Lexical (DL). Este modelo, em sua essência, propõe que as mudanças sonoras sejam vistas como sendo lexicalmente graduais e foneticamente abruptas. O modelo da DL se opõe, portanto, ao modelo Neogramático (NG), que concebe as mudanças sonoras como sendo lexicalmente abruptas e foneticamente graduais.

No modelo NG, conforme sabemos, uma mudança sonora é vista como sendo, também, (a) sem exceção e, (b) condicionada unicamente por fatores fonéticos. Os contra-exemplos são sempre tratados como casos de analogia ou de empréstimo. Assim, supõe-se para uma mudança do tipo

\section{(1)}

$\mathrm{A} \longrightarrow \mathrm{B} / \mathrm{C}$

que $\mathrm{C}$ e D sejam condicionantes fonéticas e que todas as palavras que contenham a seqüência sonora CAD sejam simultaneamente atingidas por ela. Daí se dizer que a mudança seja lexicalmente abrupta.

A literatura produzida no modelo da DL, por outro lado, tem evidenciado que muitas mudanças do tipo de (1) raramente são transparentes, se é que alguma vez o são. Freqüentemente encontramos, lado a lado, seqüências CBD e residuos - muitas vezes bastante numerosos - do tipo $\mathrm{CAD}$, que tornam o processo opaco. E, conforme se pode ler nos vários casos mencionados na literatura, estas exceções não podem se explicar por empréstimo ou analogia. Em resumo, há mudanças sonoras que não podem ser seriamente tratadas como sendo foneticamente condicionadas, se é que atribuimos ao termo condicionamento fonético algum sentido. Claro está que casos deste tipo não se ajustam num esquema NG. Exemplos desta natureza já foram levantados para o chinês (Wang (1969); Wang \& Cheng (1977); Cheng \& Wang (1977)), o sueco (Janson (1977)), o inglês (Labov (1981)), o português (Viegas (1987); Oliveira (1991)), a família dravídica (Krishnamurti (1978)), entre outros. 
Tomemos como exemplo uma regra como (2)

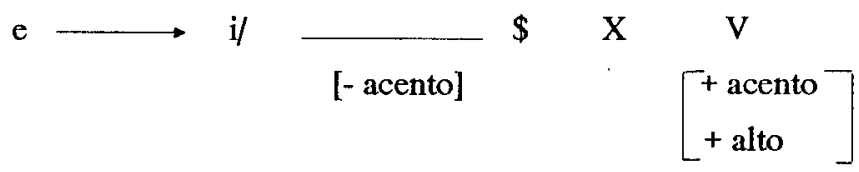

A regra (2) será satisfeita por pronúncias como 'midida' (medida) e será contrariada por pronúncias como 'medita' (medita). Note-se que estas duas pronúncias são as pronúncias registradas para o dialeto de Belo Horizonte. Note-se, também, que a regra (2), ou uma versão mais refinada da mesma, cabe dentro de uma análise variacionista clássica, como nas análises cuidadosas apresentadas por Bisol (1981) e Viegas (1987). Nestes casos, uma regra como (2) é tratada como uma regra variável. Uma vez que no dialeto em questão as únicas pronúncias encontradas são 'midida' e 'medita', não havendo, pois, variação a nivel lexical, uma análise variacionista clássica acaba escamoteando o problema na medida em que dilui o conflito num espaço entre $\emptyset \mathrm{e} 1$. Mas o fato é que, queiramos ou não, o condicionamento aqui é lexical, fora da ajuda de qualquer contexto fonético.

Temos, então, dois modelos antagônicos, DL e NG, sendo que ambos são fartamente sustentados e defendidos na literatura. Como conviver com os dois? Num texto hoje clássico, Labov (1981) tenta acomodar os dois modelos numa teoria da mudança sonora, atribuindo à competência do modelo NG as mudanças low level, e à competência do modelo DL as mudanças high level. Em texto recente (Oliveira (1991)) sugeri que todas as mudanças sonoras devam ser tratadas via $\mathrm{DL}$, e que o contexto fonético não é o fator primordial para o desencadeamento das mesmas. No presente texto quero me concentrar na questão do condicionamento fonético apregoado pelo modelo NG para, a partir daí, comentar também (a) a questão das exceções e a questão da vulnerabilidade maior ou menor de certos itens léxicos a uma mudança sonora, e (b) a questão da dimensão da variação numa abordagem difusionista.

Quero acrescentar que os dados utilizados para apoiar as hipóteses apresentadas aqui são tirados de um estudo sobre o alçamento das vogais médias pretônicas. A amostra constituiu-se dos 150 dados iniciais das entrevistas com 12 informantes de Belo Horizonte, perfazendo um total de 1800 dados. Destes, 1158 se referem ao alçamento de [e] para [i], e 642 ao alçamento de [o] para [u]. Os 12 informantes estão divididos igualmente em 4 grupos sociais: favela, operariado, classes média baixa e média alta.

\section{O PAPEL DO CONTEXTO FONÉTICO}

Em Oliveira (1991) afirmei que o contexto fonético não esclarece muita coisa no que se refere ao alçamento de vogais médias pretônicas em português. Casos como [midida] e [medita] podem ser facilmente multiplicados: [tumaci] vs [tomada], [simestri] vs [semeci], [pumada] vs [pomah], etc. E mais: pares como 'porção' vs 'purção', 'preciso' vs 'priciso', 'Senhor' vs 'sinhor', 'folhinha' vs 'fulhinha', e outros, são a melhor prova de que o contexto fonético não elucida o problema. Em casos como estes, 
aliás, o contexto fonético é a única variável que não poderia ser apontada como explicação, uma situação deveras incômoda numa abordagem NG.

Por outro lado, não há como fugir do seguinte fato: a esmagadora maioria dos itens lexicais listados por Viegas (1987:220-31) como tendo alçamento categórico das médias pretônicas tem esta média pretónica seguida por uma vogal alta na sílaba tônica. Portanto, como acomodar estes fatos num esquema em que o contexto fonético está sendo relegado a um plano secundário? A vogal alta na sílaba tônica é, ou não é, o condicionador do alçamento da média pretônica? Afinal, se afirmo que a mudança sonora em questão, ou qualquer outra, não é condicionada pelo contexto fonético imediato, como explicar esta "coincidência"?

Para começar a responder a estas perguntas, quero fazer aqui uma pequena digressão. Suponhamos, primeiramente, que nós já tenhamos uma teoria bem elaborada sobre mudanças lingüisticas. Imagino que esta teoria deveria ser capaz de se desincumbir de algumas tarefas mais ou menos óbvias, tais como:

a - dizer o que é, e o que não é, uma mudança possivel,

b - dizer que direções uma mudança possivel pode, ou não pode, tomar, e

c - dizer o que é, e o que não é, uma situação ideal para que uma mudança possivel possa se fixar.

A tarefa (a) seria tratada por princípios bastante gerais e universais. Exemplos de princípios desta natureza, se focalizarmos apenas a mudança sonora, podem ser encontrados em Labov, Yaeger \& Steiner (1972), tais como; "Vogais tensas sobem". A tarefa (b) seria tratada por princípios também gerais, porém línguo-específicos. A direção, neste caso, dependerá do encaixamento estrutural da mudança. A tarefa (c), por sua vez, implicaria na submissão dos princípios getais a avalią̧ões locais, que comentarei mais adiante.

Estou supondo, portanto, que uma teoria da mudança lingüistica, moldada conforme o esquema getal que acabei de esboçar, seja capaz de dizer, por exemplo, que

(a) - (3) e (4) são mudanças possíveis, mas (5) não é uma mudança possível

(3) $0 \longrightarrow \mathrm{X} \longrightarrow \mathrm{X}$

(4) $\mathrm{O} \longrightarrow \mathrm{u} / \mathrm{X} \longrightarrow \mathrm{Y}$

(5) $0 \longrightarrow \mathrm{X} \longrightarrow \mathrm{X}$

(b) - Dadas as características estruturais de um determinado sistema lingüístico, num ponto específico do tempo, uma mudança que atinja [o] o levará mais provavelmente a $[\mathrm{u}]$ e não a $[\supset]$, por exemplo.

(c) - Uma vez disparada a mudança, ela se acomodará mais facilmente em alguns contextos do que em outros.

Recapitulando, podemos dizer que:

$1^{2}$ - Qualquer segmento pode ser alterado, i.e., em princípio, todo segmento é instável.

$2^{2}$ - O contexto que licencia, ou não, a alteração de um segmento é o item léxico. Na verdade, o que muda é a palavra, e não o segmento (ou parte dela). 
Assim sendo, a vulnerabilidade maior ou menor de um segmento qualquer decorre da vulnerabilidade maior ou menor do ítem léxico que o contém.

$3^{2}$ - Uma vez alterado um determinado segmento (que funciona como um indicador da alteração do item léxico), ele pode se colocar numa relação harmônica ou desarmônica com os segmentos vizinhos e/ou com os suprasegmentos. Se a alteração conduzir a uma relação harmônica, as chances de que esta alteração vingue são bem maiores.

Antes de prosseguirmos, convém definir aqui o que estamos entendendo por relação harmônica. Uma relação harmônica é aquela que se constitui de aspectos (fonológicos) congruentes. Por exemplo, na maioria dos dialetos brasileiros, a ocorrência de [I] e [U] em posição final átona caracteriza uma relação harmônica, na qual encontramos vogais [-tenso]. O mesmo já não ocorre com $[\varepsilon]$ e $[\supset]$ nesta mesma posição, pois estas vogais são [+tenso]. Um outro exemplo pode ser dado por processos fonológicos como a assimilação (harmônico) e a dissimilação (desarmônico).

Vamos nos concentrar aqui no item $3^{\circ}$ acima, i.e., na questão da harmonia/desarmonia provocada por uma alteração qualquer. Mencionei, anteriormente, a questão da avaliação local. A avaliação local, conforme a concebo aqui, procura medir a probabilidade de umn determinado contexto assimilar, de modo irrestrito, uma dada inovação, ou de conduzir à flutuação entre duas formas. Claro está que estou concebendo o contex to fonético, como já foi dito, como um assimilador a posteriori, e não como um condicionador a priori de uma inovação. Dizendo de outra forma, a reestruturação lexical é mais rápida, de mais fácil acomodação, nos contextos mais expostos (e.g., posição final; coda; sílaba átona; contexto semelhante à inovação (i.e., sequiência harmônica)) enquanto que a flutuação entre duas formas é mais provável nos contextos menos expostos (e.g., posição não-final; onset; sílaba tônica; contexto diferente da inovação (i.e., seqüência desarmônica)).

Finalmente, uma palavra a respeito da questão da flutuação entre formas. Devemos distinguir aqui entre dois tipos diferentes de flutuação. A primeira delas é aquela que podemos chamar de flutuação fonética, da qual me ocupo na seção 5 . Na flutuação fonética vamos encontrar os casos legítimos de variação; são casos onde podemos encontrar tanto $[\mathrm{x}]$ quanto $[\mathrm{y}]$ num mesmo ambiente. Nestes casos um determinado morfema aparece, realmente, em duas composições fonéticas, num mesmo contexto. Temos, então, tanto $\{[x] \mathrm{W}\}$ quanto $\{[y] \mathrm{W}\}$, e um exemplo disto seria a possibilidade de se ter [ku'migU] e [ko'migU] para comigo.

A segunda delas é aquela que podemos chamar de flutuação alomórfica, ou flutuação automática, da qual me ocupo na seção 3 . Na flutuação alomórfica vamos encontrar os casos falsos de variação (muito embora sejam contados como casos de variação legítima em alguns estudos) já que cada uma das formas tem um locus específico de ocorrência. Nestes casos um determinado morfema aparece em composições fonéticas diferentes em ambientes diferentes. Temos, então, $\{[x] \mathrm{W}\}$ e $\{[y] \mathrm{J}\}$ ( mas não * $\{[\mathrm{x}] J\}$ e/ou * $\{[y] W\}$ ). Um exemplo deste caso pode ser dado, para o dialeto do qual me ocupei, por [ku'hi] 'corri' vs [ko'hew] 'correu' (mas não *[ko'hi] e/ou *[ku'hew]). Retomarei estes casos nas seções 3 e 5. 


\section{FLUTUAÇÃO ALOMÓRFICA}

Uma vez caracterizada a flutuação alomórfica, tomemos, como exemplos, alguns verbos que surgiram no corpus examinado. Alguns destes verbos aparecem sempre com alçamento, independentemente do contexto fonético:

- 'cumendo', 'cumia', 'cumer' (8 formas)

- 'cumeça', 'cumeçava', 'cumecei', 'cumeçou', 'cumeçamos' (30 formas)

- 'cunversar', 'cunversava', 'cunversa' (5 formas)

Por outro lado, alguns verbos aparecem sempre sem alçamento, tais como:

- 'acontece', 'aconteceu', 'acontccia', 'acontecido' (9 formas)

- 'consegui', 'consegue', 'conseguia', 'conseguido', 'conseguir' (11 formas)

Mas os casos mais interessantes são exatamente aqueles em que algumas formas de um verbo sempre apresentam alçamento, enquanto que outras nunca apresentam alçamento. Casos deste tipo podem ser exemplificados por:

$$
\begin{aligned}
& \text { - 'curri', 'currido' vs 'correu', 'correndo', 'correr' } \\
& \text { - 'murri', 'murria', 'murrido' 'morter', 'morreu' } \\
& \text { - 'pudia', 'pudido' 'poder', 'podemos' }
\end{aligned}
$$

Ou seja, no português de Belo Horizonte não há nada como 'corri', 'morri', 'podia' ou 'podido', muito embora estas formas sejam perfeitamente aceitáveis e ocorrentes em outros dialetos. Da mesma forma, não temos, em Belo Horizonte, nada como 'curreu', 'murreu', 'puder', e outras, muito embora estas formas sejam perfeitamente aceitáveis e ocorrentes no português europeu e em algumas modalidades do português brasileiro. A questão é: o que é que estes casos nos mostram? Eles nos mostram que:

1 - Uma mudança é licenciada lexicalmente, e cada dialeto terá a sua própria lista de itens atingidos, independentemente de contex to fonético. Estas listas poderão não só ter tamanhos diferentes mas conterão, também, elementos diferentes.

2 - Uma vez atingido, o item em questão se submete à avaliação local. A depender das circunstâncias estruturais, isto pode levar à reestruturação (imediata ou não) ou à flutuaçáo (variável ou automática).

3 - Os casos de flutuação poderão ser revertidos, ou então nivelados em termos da inovação, o que levaria à reestruturação. Estes ajustes finos serão resolvidos dialetalmente ou mesmo individualmente.

Muito embora eu nunca tenha registrado um caso de reversão, ainda assin sou levado a admitir a possibilidade de sua existência, uma vez que algumas hipercorreções (casos como 'menistro', 'entestino', 'anelina', etc) sugerem exatamente isto. Já o nivelamento em termos da inovação, levando à reestruturação lexical, é bastante provável. $\mathrm{Na}$ verdade estou supondo que foi exatamente isto o que aconteceu em casos como 'cumi'-'cumeu', onde a inovação se propagou da primeira forma para a segunda. Note-se, inclusive, que não há nenhum dialeto, pelo menos ao que me conste, onde a alomorfia seja do tipo 'comi'-'cumen', ou 'morri'-'murreu', ou 'podia'-'puder'. Estes 
fatos, aliás, me parecem uma confirmação bastante forte da atuação de uma avaliação local nos casos de inovação.

Finalmente, podemos dizer que casos como 'curri'-'correu' descartam a possibilidade de ser apenas por mero acaso que a maior parte das palavras com alçamento categórico contenha uma vogal alta.

\section{QUE ITEM LEXICAL ABRE AS PORTAS PARA A MUDANÇA?}

Em Oliveira (1991) sugeri que as palavras que são afetadas em primeiro lugar por uma mudança teriam certos traços, tais como [+ Comum], [+ Estilo Informal] e [+ Contexto Fonético Natural para a Inovação]. Contudo, conforme vimos, estou propondo agora que se considere o contexto fonético em um outro nível, não mais como um condicionador e sim como uma espécie de estabilizador de uma inovação, funcionando a nível lexical. Também o traço [+ Estilo Informal] pode, e deve, ser substituído por um traço lexical como, por exemplo, [- Elaborado]. Com isto podemos remover dos traços inerentes das palavras quaisquer considerações de ordem estilística, embora seja evidente que palavras marcadas como [- Elaborado] tendam a ocorrer em contextos informais. Deixando de lado, aqui, os detalhes do traço [Elaborado], vou me restringir à questão do traço [Comum].

Em pelo menos mais dois trabalhos neste volume, o de Mattos \& Mollica e o de Gonçalves, encontramos evidência de que palavras marcadas como [- Coinum] atuam como bloqueadores de mudanças. Note-se, além disso, que mesmo os processos sem qualquer tipo de condicionamento acabam sendo cerceados por palavras marcadas como [- Comuin]. Um exemplo disto pode ser dado pelo processo de monotongação de [ow] para [o]. Este processo não tem condicionamento, uma vez que qualquer ditongo [ow] pode ser monotongado em [o]: outro, couro, falou, ouvir, açougueiro, etc. Contudo, a redução do ditongo não se dá em palavras como Ourinhos, Rebouças, Moscou, Gouveia ou Couto, todas elas [- Comum]. As palavras eruditas e as especializadas, como grou, têm um comportamento bastante parecido com o das palavras [Comum], tendendo a inibir mudanças. Por exemplo, em três ocorrências da palavra gueixa, na entrevista de um informante não utilizado no corpus que examinei para este trabalho, não ocorreu nenhuma redução do ditongo [ey], muito embora este ditongo tenha sido reduzido a [e] nas duas ocorrências da palavra deixa e nas duas ocortências da palavra deixei, todas da entrevista deste mesmo informante. Estes fatos sugerem muito fortemente que itens lexicais marcados como [- Comum] ([+ Erudito], [+ Especializado] e, muito possivelmente, outros mais) são, de fato, mais resistentes à mudança. Neste sentido podemos dizer, também, que as exceções são, pelo menos em parte, previsíveis, e não precisam ser tratadas como foras-da-lei. E, para fechar esta seção, quero dizer que considero o tratamento do léxico como sendo a parte mais obscura de toda esta questão. Acho, inclusive, que uma teoria lexical só pode ser elaborada se dispusenmos de uma teoria da linguagem (e não de teorias da gramática), o que ainda não temos.

\section{A DIMENSÃO DA VARIAÇÃO NA ABORDAGEM DIFUSIONISTA}

Nesta última seção quero tratar, ainda que brevemente, da questão da flutuação fonética. Como se disse anteriormente, os casos de flutuação fonética, conforme os caracterizamos, são aqueles que podem se candidatar a casos legítimos de variação. 
Por aquilo que vimos até aqui, podemos tirar algumas consequiências, que nos permitirão redimensionar a questão da variação, mesmo em termos da flutuação fonética. Até aqui vimos que:

1 - Dialetos diferentes possuem listas diferentes (tanto em termos de tamanho quanto em termos de elementos contidos na lista) de itens afetados por uma dada inovação. A conseqüência distoé que as diferenças inter-dialetais, com relação a uma inovação qualquer, serão sempre maiores do que as diferenças intra-dialetais.

2 - Dentro de uma mesma comunidade de fala a dimensão da varią̧ão fica consideravelmente reduzida uma vez que não podem ser computados os itens que, naquele dialeto, são ou categoricamente atingidos ou categoricamente não-atingidos. Um exemplo disto pode ser dado, como vimos, pelo processo de alçamento das pretônicas no português de Belo Horizonte.

3 - Os itens analisáveis em ternos de flutuação alomórfica só poderão ser computados como variáveis se estiverem sofrendo um processo de reversão (caso que nunca registrei) ou um processo de nivelamento em direção da inovação. Se, contudo, a situação for estável, também estes casos deverão ser desconsiderados em termos de variação.

Observe-se que 2 e 3 acima já reduzem bastante o número dos dados que poderão ser levados em conta para a análise da variação, uma vez que eles simplesmente não são variáveis. Voltamos, então, em 4 abaixo, ao tema desta seção:

4 - Serão computados como variação apenas os casos onde uma mesma palavra ocorra tanto na forma CAD quanto na forma CBD, dada uma regra (6)

(6)

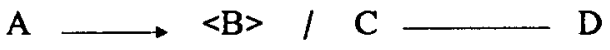

A questão que se coloca agota é a seguinte: existe a situação indicada em 4 acima?

Para responder à questão colocada, vamos examinar alguns números. Para tanto, vou me restringir aqui aos 642 casos de /o/ pretônico. Se considerarmos todos estes dados de uma só vez, numa abordagem variacionista clássica, vamos encontrar 156 casos de alçamento, o que nos dá um percentual geral de $24,3 \%$. Noentanto, para poder acompanhar o desempenho dos itens lexicais e de cada um dos 12 informantes, trabalhei, num segundo momento, apenas com as palavras que ocorreram pelo menos 3 vezes no corpus examinado. Foram selecionadas, então, 26 palavras, cujo número de ocorrências variava de 3 a 30 , perfazendo um total de 251 casos. O interessante é que destas 26 palavras, apenas 3 - jogar, comigo, português - se enquadram na categoria da flutuação fonética, sendo, pois, possiveis casos de variação. As outras 23 palavras são:

(a) - Com [o] categótico: morar, gostar, conseguir, acontecer, sozinho.

(b) - Com [u] categórico: começar, conhecer, dormir, porque, comer, conversar, governo, notícia, sobrinho, acostumar, domingo, bonito, costumar, doente. 
(c) - Com flutuação alomórfica: 'morreu-murri', 'poder-pudia', 'correr-curri', 'sofrer-sufrida'.

Ou seja, em 251 casos encontrados, apenas 20 (jogar-12, comigo-12 e português-6) podem, em princípio, ser considerados como casos legítimos de variação. Em princípio, mas não de fato, como veremos.

Vejamos caso por caso:

\section{Caso 1 - jogar}

As formas do verbo jogar aparecem nas entrevistas de 3 informantes, nos $1,6 \mathrm{e} 11$, da seguinte maneira:

$\begin{array}{lll}\begin{array}{l}\text { Forma } \\ \text { jogar }\end{array} & \text { Informante } & \text { Registro } \\ \text { jogada } & 1 & \mathbf{o}, \mathrm{o}, \mathrm{o}, \mathrm{o} \\ \text { jogado } & 11 & \mathbf{u} \\ \text { jogava } & 11 & \mathbf{u} \\ & 1 & \mathbf{o} \\ \text { jogando } & 11 & \mathbf{u} \\ \text { jogavam } & 1 & \mathbf{o}, \mathrm{o} \\ \text { jogou } & 6 & \mathbf{o} \\ & 1 & \mathbf{o}\end{array}$

Total: 12

O que acontece aqui é bastante interessante: as três ocorrências de [u] são devidas a um mesmo informante, $o n^{2} 11$, que, além do mais, não produziu nenhuma ocorrência de [o]. A situação inversa ocorre com os informantes 1 e 6 . Ou seja, pelo que se pode ver, não há variação a nível individual: o informante 11 tem as formas do verbo jogar na lista do [u]-categórico, enquanto que os informantes 1 e 6 as têm na lista do [o]-categórico. Numa análise variacionista clássica, tendo como perspectiva o grupo, teríamos um percentual de $25 \%$ de alçamento. Contudo, na perspectiva do indivíduo o percentual de variação é $0 \%$ ! Sugiro, então, mesmo correndo o risco da heresia, que o comportamento do individuo é mais homogêneo do que o comportamento do grupo.

Caso 2 - comigo

Os 12 casos de comigo se distribuem, por informante e por registro, da seguinte maneira:

$\begin{array}{ll}\text { Informante } & \text { Registro } \\ 1 & \mathrm{o}, \mathrm{o}, \mathrm{o}, \mathrm{u}, \mathrm{u} \\ 4 & \mathrm{u}, \mathrm{u}, \mathrm{u} \\ 5 & \mathrm{u} \\ 6 . & \mathrm{u} \\ 10 & \mathrm{u} \\ 12 & \mathrm{o}\end{array}$


Os dados aqui não são tão claros quanto os do Caso 1, uma vez que estão pulverizados entre muitos informantes. Assim sendo, fica difícil de se dizer qualquer coisa além de: (a) há variação para o informante $n^{\circ} 1, e$ (b) não há variação para o informante $n^{\circ} 4$.

\section{Caso 3 - português}

O Caso 3 introduz um aspecto diferente do problema, que é o da especialização semântica das formas com [o] e das formas com [u]. Os 6 casos se distribuem da seguinte maneira:

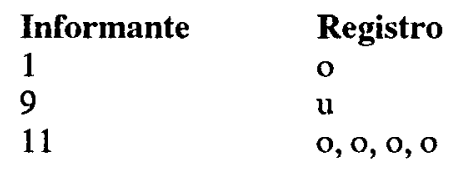

Sendo que formas como 'português' significam 'língua portuguesa' ou a disciplina escolar que se ocupa do estudo da nossa língua, enquanto que formas como 'purtuguês' significam 'natural de Portugal', simplesmente não há variação. Casos como este são semelhantes a pares do tipo:

$\begin{array}{lll}\text { 'porção' } & \text { vs } & \text { 'purção' } \\ \text { 'folhinha' } & \text { vs } & \text { 'fulhinha' } \\ \text { 'fogão' } & \text { vs } & \text { 'fugão' } \\ \text { 'veado', 'Veado' } & \text { vs } & \text { 'viado', etc }\end{array}$

\section{CONCLUSÃO}

\section{Concluindo}

$1^{2}$ - Não é verdade que uma abordagem difusionista da mudança sonora deva ignorar, ou se esconder de, as 'coincidências' fonéticas encontradas. Estas 'coincidências' deixam de ser 'coincidências' se entendermos o contexto fonético não como condicionador de inovações, mas como um respaldo local para a fixação da inovação em determinados itens lexicais.

20 - A flutuação alomórfica estável não se qualifica como caso de variação. A não ser que haja reversão do processo, ou nivelamento na dirę̧ão da inovação, estes casos não podem ser contados. Também não podem ser contados como variação os casos de flutuação fonética resolvidos em termos de especialização semântica.

$3^{2}$ - Ainda precisamos de muito trabalho no que se refere ao papel do léxico na mudança sonora. As razões que levam um item lexical a ser mais, ou menos, vulnerável a uma inovação ainda são obscuras.

$4^{9}$ - A menos que haja alguma razão séria em contrário, sugiro que o comportamento individual seja checado para todos os itens lexicais. Somente depois disto é que os indivíduos poderão ser agrupados, se isto for possivel. A divisão da comunidade de fala em grupos (ou classes, ou estratos) não é, necessariamente, o último estágio da divisão. $\mathrm{Na}$ verdade, ninguém demonstrou ainda que esta fosse a divisão correta. 


\section{REFERÊNCIAS BIBLIOGRÁFICAS}

CHENG, C-C., WANG, W.S-Y. Tone change in Chao-zhou Chinese: A study inlexical diffusion. In: WNAG, W.S-Y. (ed.) The lexicon in phonological change. The Hague: Mouton, 1977. p. 86-100.

JANSON, Tore. Reversed lexical diffusion and lexical split: loss of - $\mathrm{d}$ in Stockholm. In: WANG, W. S-Y. (ed.) The lexicon in phonological change, W.S-Y. Wang (ed.), 252-265. The Hague: Mouton.

KRISHNAMURTI, B. Areal and lexical diffusion of sound change. L a n g u a ge , v. 54, n. 1, p. 1-20, março, 1978.

LABOV, W. Resolving the neogrammarian controversy. L a n g u a g e , v. 57, n. 2, p. 267-308, junho, 1981.

LABOV, W., YAEGER, M., STEINER, R. A quantitative study of sound change in progress. Philadelphia: US Regional Survey, 1972.2v.

OLIVEIRA, Marco A. The neogrammarian controversy revisited. International journal of the sociology of language. Berlin, v.89, p.93-105, 1991

VIEGAS, Maria do Carmo. Alçamento de vogais médias pretônicas: uma abordagem sociolingüística. Belo Horizonte: UFMG, 1987.231 p. Dissertação (Mestrado), Faculdade de Letras, Universidade Federal de Minas Gerais.

WANG, W.S-Y. Competing changes as a cause of residues. Language, v.45, n.1, p.9-25, março, 1969.

WANG, W.S-Y., CHENG, C-C. Implementation of P h o n ol og i c a 1 Change: TheShuang-feng Chinese Case. In: wang, w.s-y. (ed.) The lexicon in phonological change. The Hague: Mouton, 1977. p.148-158. 